\title{
Cellular calcium in bipolar disorder: systematic review and meta-analysis
}

\author{
Paul J. Harrison $\mathbb{1}^{1,2} \cdot$ Nicola Hall $\mathbb{1}^{1} \cdot$ Arne Mould ${ }^{1,2} \cdot$ Noura Al-Juffali ${ }^{1,2} \cdot$ Elizabeth M. Tunbridge ${ }^{1,2}$
}

Received: 16 August 2019 / Revised: 20 November 2019 / Accepted: 22 November 2019 / Published online: 4 December 2019

(c) The Author(s) 2019. This article is published with open access

\begin{abstract}
Calcium signalling has long been implicated in bipolar disorder, especially by reports of altered intracellular calcium ion concentrations $\left(\left[\mathrm{Ca}^{2+}\right]\right)$. However, the evidence has not been appraised critically. We carried out a systematic review and metaanalysis of studies of cellular calcium indices in bipolar disorder. 2281 records were identified and 117 screened, of which 32 were eligible and 21 were suitable for meta-analyses. The latter each involved up to 642 patients and 404 control subjects. We found that basal free intracellular $\left[\mathrm{Ca}^{2+}\right]$ is increased in bipolar disorder, both in platelets and in lymphocytes. The effect size is 0.55 , with an estimated elevation of $29 \%$. It is observed in medication-free patients. It is present in mania and bipolar depression, but data are equivocal for euthymia. Cells from bipolar disorder individuals also show an enhanced $\left[\mathrm{Ca}^{2+}\right]$ response to stimulation with 5-HT or thrombin, by an estimated $25 \%$, with an effect size of 0.63 . In studies which included other diagnoses, intracellular basal $\left[\mathrm{Ca}^{2+}\right]$ was higher in bipolar disorder than in unipolar depression, but not significantly different from schizophrenia. Functional parameters of cellular $\mathrm{Ca}^{2+}$ (e.g. calcium transients), and neuronal $\left[\mathrm{Ca}^{2+}\right]$, have been much less investigated, and no firm conclusions can be drawn. In summary, there is a robust, medium effect size elevation of basal and stimulated free intracellular $\left[\mathrm{Ca}^{2+}\right]$ in bipolar disorder. The results suggest altered calcium functioning in the disorder, and encourage further investigations into the underlying mechanisms, and the implications for pathophysiology and therapeutics.
\end{abstract}

\section{Introduction}

The possible involvement of calcium ions $\left(\left[\mathrm{Ca}^{2+}\right]\right)$ in bipolar disorder has been under investigation for almost a 100 years [1]. Researchers have compared a range of $\mathrm{Ca}^{2+}$ parameters between cases and controls, but following landmark studies in the late 1980s [2, 3], the main focus has been upon intracellular calcium ion concentrations $\left(\left[\mathrm{Ca}^{2+}\right]\right)$, predominantly in platelets and lymphocytes. The postulated links between $\mathrm{Ca}^{2+}$ and bipolar disorder are usually interpreted in the context of the fundamental roles of $\mathrm{Ca}^{2+}$ in neuronal excitation, transmitter synthesis and release, and

Supplementary information The online version of this article (https:// doi.org/10.1038/s41380-019-0622-y) contains supplementary material, which is available to authorised users.

Paul J. Harrison

paul.harrison@psych.ox.ac.uk

1 Department of Psychiatry, Warneford Hospital, University of Oxford, Oxford OX3 7JX, UK

2 Oxford Health NHS Foundation Trust, Oxford, UK synaptic function and plasticity [4-8]. Researchers also noted the effects of abnormal $\mathrm{Ca}^{2+}$ levels on mood (e.g. in hyperparathyroidism), and the fact that lithium and some other psychotropic drug classes alter $\mathrm{Ca}^{2+}$ functioning [9-11].

Over the past decade the study of $\mathrm{Ca}^{2+}$ in bipolar disorder has been received new impetus from the increasingly compelling evidence that voltage-gated calcium channels (VGCCs) are part of the genetic aetiology [12, 13]. Interest is enhanced by the therapeutic opportunities which VGCCs provide, given their known druggability by existing calcium channel blockers and the gabapentinoids [14-17]. However, despite multiple studies and several narrative reviews, there is no consensus as to the specific $\mathrm{Ca}^{2+}$ abnormality-if any -which characterises bipolar disorder, nor is the robustness of the evidence clear [18-20]. To address this gap, we have systematically reviewed and meta-analysed the literature regarding cellular $\mathrm{Ca}^{2+}$ in bipolar disorder.

\section{Materials and methods}

We registered our study on the PROSPERO international prospective register of systematic reviews (http://www. 
crd.york.ac.uk/PROSPERO/display_record.php?ID=CRD 42019119254). The primary question we wished to answer was: Does cellular $\left[\mathrm{Ca}^{2+}\right]$ differ in cells from individuals with bipolar disorder compared with healthy controls, either at baseline or in response to stimulation? Our secondary analyses included comparisons between different cell types; between depressed, euthymic and manic states; and between bipolar I and II disorder. We also assessed cellular $\left[\mathrm{Ca}^{2+}\right]$ in medication-free individuals, and addressed diagnostic specificity by examining studies which directly compared bipolar disorder with schizophrenia or unipolar depression. Finally, we reviewed studies in which other parameters of cellular $\mathrm{Ca}^{2+}$ had been measured.

Given these objectives, we aimed to identify all studies in which individuals with bipolar disorder were compared with healthy controls, and which measured one or more of the following parameters: intracellular $\mathrm{Ca}^{2+}$ concentrations, at baseline or after stimulation; measures of calcium flux or mobilisation; calcium-mediated electrophysiological signals. All cell types (including those derived from induced pluripotent stem cells [iPSC]) were included. We did not consider data which were only published in abstracts, or in non-peer reviewed publications (e.g. book chapters), or in languages other than English. We excluded studies of blood or other body fluids, and studies measuring calcium-related molecules such as calcium channels, calcium-binding proteins, $\mathrm{Ca}^{2+}$-ATPase, or TRPC7. We also excluded animal models of bipolar disorder.

To identify relevant studies we searched the Web of Science, All Databases, refined to the Web of Science Core Collection and Medline. The search terms were (calcium or $\mathrm{Ca}^{2+}$ ) and ('bipolar disorder' or 'bipolar disease' or 'bipolar I' or 'bipolar II' or 'bipolar depression' or 'manicdepressi*' or 'manic depressi*' or 'affective' or 'mania' or 'manic'). In addition, we searched the reference list of all eligible studies, all citations of eligible studies, and our own reprint collections. The last search was on 18th July 2019.

Titles and abstracts of studies retrieved by the search strategy were screened independently by two of the authors. The full text of all potentially eligible articles (and, where relevant, their supplementary information) was also obtained and independently assessed by two authors. We resolved any ambiguities about eligibility through discussion. The extracted information comprised: year of publication; numbers of cases and controls; diagnostic criteria for bipolar disorder; subtype of bipolar disorder; cell type; mood state of cases (manic, euthymic, depressed, or not stated); medication status of cases; methodology used; $\mathrm{Ca}^{2+}$ parameter(s) measured; mean and standard deviation of eligible datasets. Where necessary, we converted standard errors and confidence intervals to standard deviations. Graphical data were extracted using WebPlotDigitizer version 4.1 (https://automeris.io/WebPlotDigitizer/). Two authors independently extracted data; we resolved any discrepancies by discussion with other authors. We contacted study authors where aspects of the data were unclear. Most measures of quality assessment (e.g. randomisation) do not apply to a systematic review of this kind; however we did check whether the study reported whether analyses wereconducted blind to diagnosis, and whether all subjects were accounted for in the analyses.

Where three or more studies used a comparable measure of $\mathrm{Ca}^{2+}$, we pooled their results using random effects metaanalysis in Cochrane Community Review Manager 5.3 (https://community.cochrane.org/help/tools-and-software/ revman-5), with standardised mean differences, 95\% confidence intervals and two-sided $p$ values for each outcome. Where subgroups needed to be combined, we used the formula for weighted means in the Cochrane handbook (https://handbook-5-1.cochrane.org/). We assessed heterogeneity using the $I^{2}$ statistic and $\chi^{2}$ test.

\section{Results}

A PRISMA diagram is shown (Fig. 1). We identified 2281 articles from our search strategy, and after screening 117 papers we identified 32 studies meeting our criteria for inclusion in the systematic review [2, 3, 21-50]. Eighty-five other studies were reviewed but excluded; they are listed in Supplementary Table 1, along with their reason for exclusion. These included several instances where the same data were reanalysed or subsumed in a second publication; we are grateful to authors who clarified these issues. Regarding the measurable quality indices, all subjects were accounted for in all studies, but no studies commented on blinding.

The 32 studies in the systematic review were published between 1988 and 2017. The majority used platelets $(n=$ $22)$; lymphocytes were used in four studies, and transformed cells (B-lymphoblasts and iPSC-derived neurons) used in six. Some studies used more than one cell type. The commonest parameters measured were basal $\left(\left[\mathrm{Ca}^{2+}\right]_{\mathrm{b}} ; n=\right.$ 22) and stimulated $\left(\left[\mathrm{Ca}^{2+}\right]_{\mathrm{s}} ; n=20\right)$ free intracellular calcium ion concentration. The most widely used stimulants were 5-hydroxytryptamine $(5-\mathrm{HT} ; n=8)$ and thrombin $(n=7)$. The standard methodology for these studies was to use Fura2, a high affinity calcium indicator dye. Studies using neurons mostly measured electrophysiological rather than biochemical parameters of $\mathrm{Ca}^{2+}(n=5)$.

Study sample sizes ranged from 2 to 215 bipolar disorder cases and 2-70 controls. Diagnoses were made using DSMIII $(n=3)$, DSM-IIIR $(n=12)$, DSM-IV $(n=10)$, other $(n=4)$, or unstated $(n=3)$ criteria. Some studies included one or more other psychiatric disorder groups, notably unipolar depression $(n=10)$ and schizophrenia $(n=5)$. Within bipolar disorder, some studies did not note (or did 
Fig. 1 PRISMA statement.

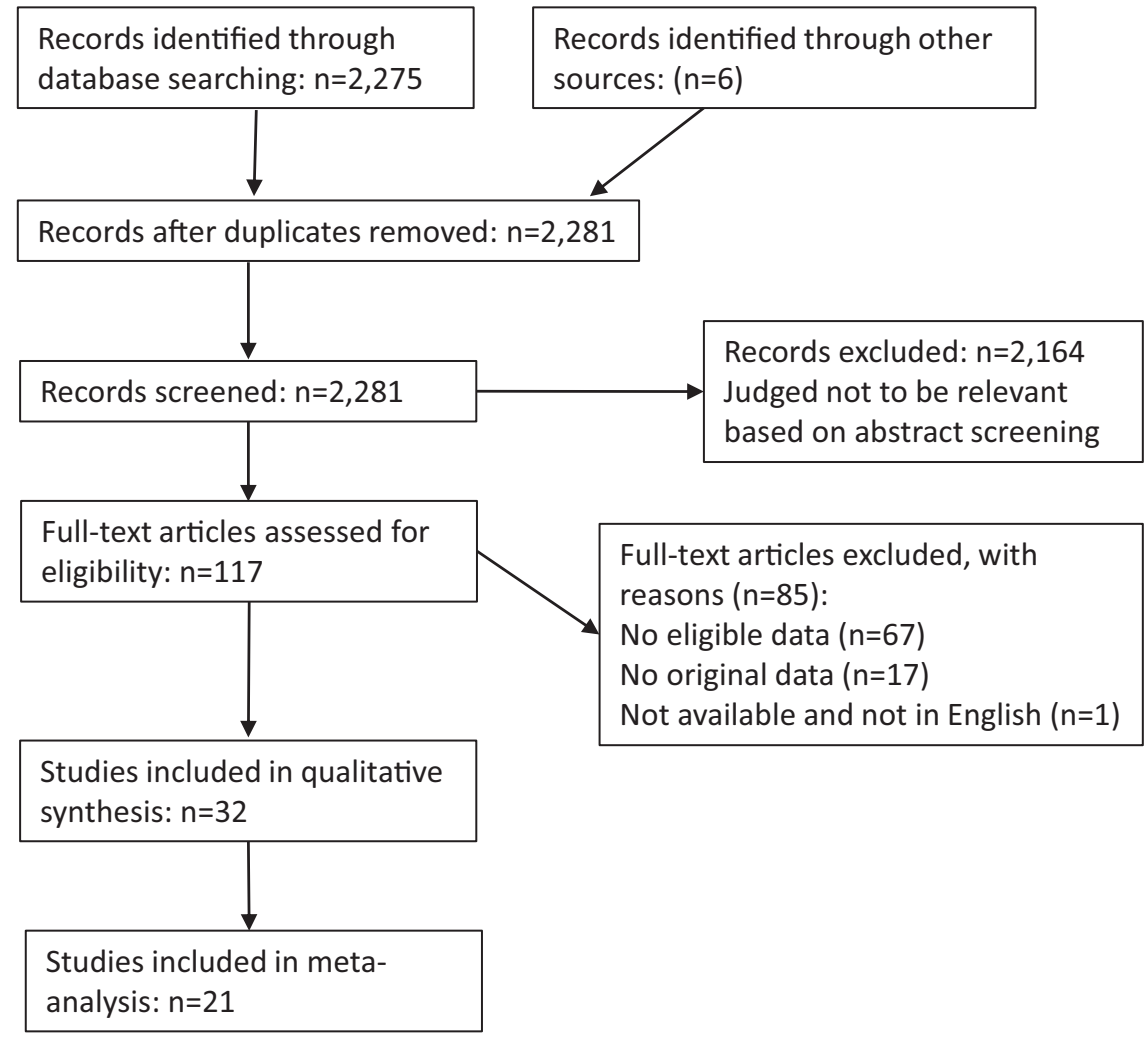

not separate) mood states, but the majority included one or more subgroups defined as being depressed, manic, or euthymic (in remission) at the time of sampling.

\section{Meta-analyses of basal cellular $\mathrm{Ca}^{2+}$ concentration}

\section{Bipolar disorder versus controls}

After exclusion of duplicate datasets, 20 eligible metaanalysable studies measuring $\left[\mathrm{Ca}^{2+}\right]_{\mathrm{b}}$ in bipolar disorder (all mood states and cell types combined, $n=642$ ) and controls $(n=404)$ were identified (Fig. 2). Meta-analysis shows elevated $\left[\mathrm{Ca}^{2+}\right]_{\mathrm{b}}$ in bipolar disorder $(n=23$ datasets; $Z=3.91$, $p<0.0001$; SMD 0.55, 95\% confidence interval 0.27-0.82). The mean increase of $\left[\mathrm{Ca}^{2+}\right]_{\mathrm{b}}$ in bipolar disorder was $29 \%$ (range $-54-152 \%)$. The increase is significant in studies of platelets ( $n=16$ datasets, of 336 patients and 268 controls; $Z=3.87, p<0.0001$; SMD 0.58 [0.29-0.88]) and lymphocytes ( $n=4$ datasets, of 61 patients and 38 controls; $Z=4.04$, $Z=4.04, p<0.0001$, SMD 0.97 [0.50-1.44]); the result in the category of 'other cells' (B-lymphoblasts and olfactory neurons) is not significant, but there is no overall heterogeneity between cell types $(p=0.16)$.

\section{Effect of mood state}

The majority of studies allowed separate comparisons to be made for mania, euthymia, and depression (Fig. 3).
Compared with controls, $\left[\mathrm{Ca}^{2+}\right]_{\mathrm{b}}$ was elevated in mania ( $n=5$ datasets, of 68 patients and 92 controls; $Z=4.05$, $p<0.0001$; SMD 0.69 [0.36-1.03]) and in bipolar depression ( $n=8$ datasets, of 99 patients and 134 controls; $Z=$ 2.60, $p=0.009$; SMD 1.10 [0.27-1.93]). However, in remission, $\left[\mathrm{Ca}^{2+}\right]_{\mathrm{b}}$ did not differ from controls $(n=7$ datasets, of 74 patients and 110 controls; $Z=1.15, p=$ 0.25; SMD 0.27 [-0.19-0.72]).

\section{Effect of medication}

We also examined results of studies in which only unmedicated patients were included. In three of these studies the subjects were drug naïve $[25,26,30]$; in the others they had been drug free for between 2 weeks and 3 months. Figure 4 shows that there was an elevated $\left[\mathrm{Ca}^{2+}\right]_{\mathrm{b}}$ in unmedicated bipolar disorder $(n=14$ datasets, of 198 patients and 244 controls; $Z=4.69, p<0.00001$; SMD 0.49 [0.28-0.69]). The increase was significant in mania $(n=2$ studies, of 36 patients and 35 controls; $Z=2.01, p=0.04$, SMD 0.50 [0.01-0.98], in bipolar depression ( $n=6$ studies, of 95 patients and 114 controls; $Z=3.56, p=0.0004$; SMD 0.55 [0.25-0.85]), and in five studies, in which mood state was either unknown or different states were grouped together ( $n=6$ datasets, of 67 patients and 95 controls; $Z=2.36$, $p=0.02$; SMD 0.41 [0.07-0.74]). There were no metaanalysable studies of unmedicated euthymic patients as only one study included such a group [40]. 


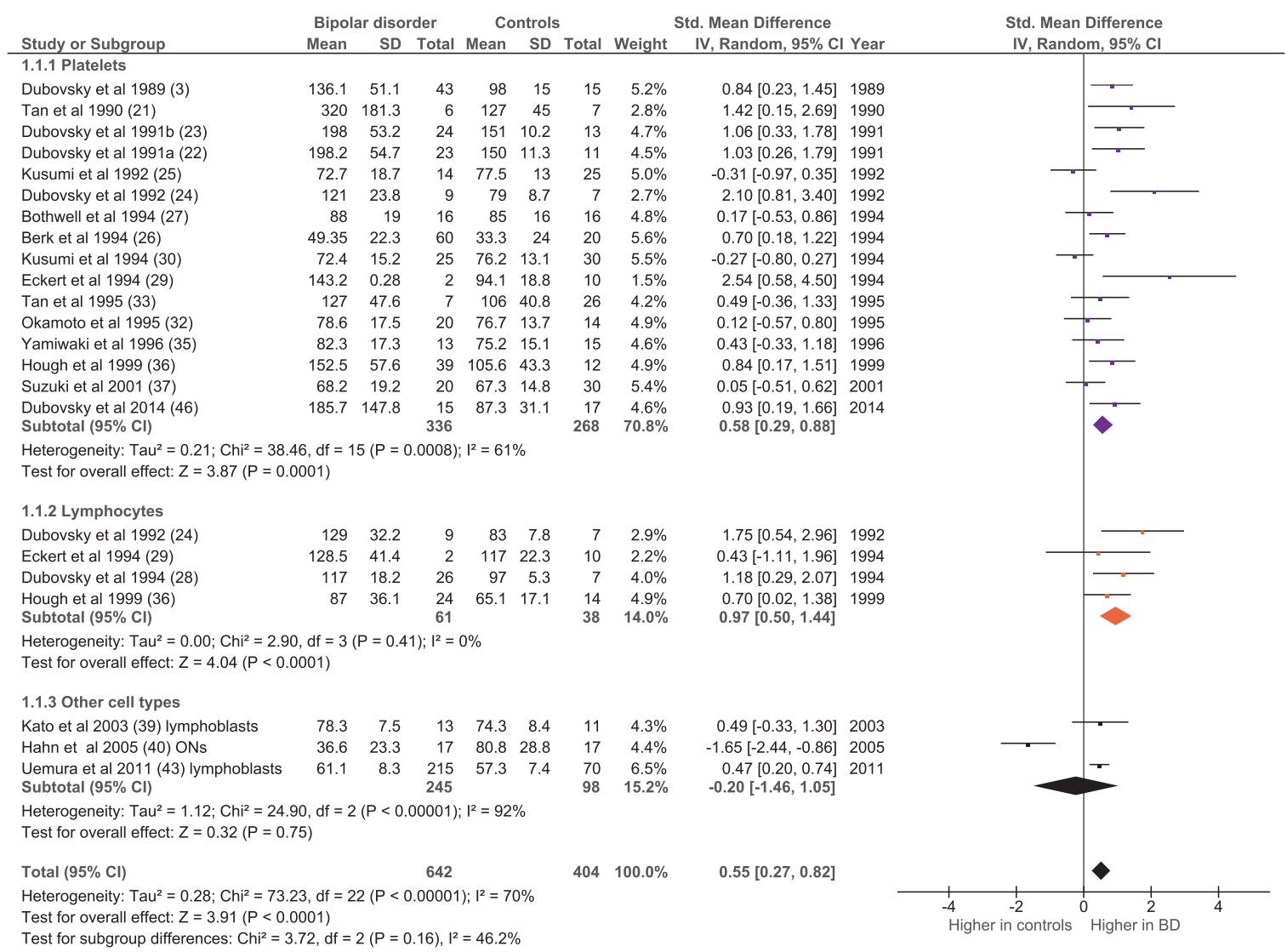

Fig. 2 Forest plot showing basal intracellular $\left[\mathrm{Ca}^{2+}\right]$ in bipolar disorder compared with controls, both overall and in platelet (purple), lymphocyte (orange) and other cell type (dark grey) subgroups. IV inverse variance, ONs olfactory neurons.

\section{Bipolar disorder compared with other diagnoses}

As shown in Fig. $5,\left[\mathrm{Ca}^{2+}\right]_{\mathrm{b}}$ in bipolar disorder was significantly higher than in unipolar depression $(n=12$ datasets, of 436 bipolar disorder individuals and 260 with unipolar depression; $Z=2.93, p=0.003$; SMD 0.36 $[0.12-0.61])$. There was no significant difference in $\left[\mathrm{Ca}^{2+}\right]_{\mathrm{b}}$ between bipolar disorder and schizophrenia, albeit based on a much smaller sample size $(n=4$ datasets, of 56 bipolar disorder individuals and 62 with schizophrenia; $Z=1.48$, $p=0.14$; SMD $0.29[-0.09-0.67])$.

\section{Meta-analyses of cellular $\mathrm{Ca}^{2+}$ concentration after stimulation with 5-HT or thrombin}

Intracellular $\left[\mathrm{Ca}^{2+}\right]$ is regulated by a range of extrinsic stimuli. A number of studies have therefore examined $\left[\mathrm{Ca}^{2+}\right]_{\mathrm{s}}$ in bipolar disorder, in addition to or instead of $\left[\mathrm{Ca}^{2+}\right]_{b}$. The most commonly used stimulants are 5-HT and thrombin. Both were amenable to meta-analysis, which showed an enhanced response in bipolar disorder $(n=16$ datasets, of 307 patients and 271 controls; $Z=4.81, p<0.0001$; SMD 0.63 [0.28-1.06]; Fig. 6). The mean increase of
$\left[\mathrm{Ca}^{2+}\right]_{\mathrm{s}}$ in bipolar disorder was $25.2 \%$ (range $-25.9-75.7 \%)$. The effect was significant for 5-HT $(n=9$ datasets, of 216 patients and 164 controls; $Z=3.29, p<$ 0.001 ; SMD 0.60 [0.24-0.95]) and for thrombin $(n=7$ datasets, of 91 patients and 107 controls; $Z=3.38, p=$ 0.0007; SMD 0.67 [0.28-1.06]).

Both stimulants were used across a range of doses, and in some studies the dose was unclear. The significantly greater responses in bipolar disorder than controls remained if analyses were restricted to the commonest concentration used in these studies $(10 \mu \mathrm{M} 5-\mathrm{HT} ; Z=5.78, p<0.00001$; SMD $0.90[0.59-1.20])$ and thrombin $(0.1 \mathrm{U} / \mathrm{ml} ; Z=3.79$, $p=0.0001$; SMD 0.81 [0.39-1.22]). Two studies used more than one concentration of 5-HT: Berk et al. (ref. 31) used $100 \mathrm{nM}, 500 \mathrm{nM}$ and $1 \mu \mathrm{M}$, and Kusumi et al. (ref. 30) used $300 \mathrm{nmol}$ and $10 \mu \mathrm{mol}$. In both instances, the enhanced $\left[\mathrm{Ca}^{2+}\right]_{\mathrm{S}}$ response in bipolar disorder was of similar magnitude at each concentration tested.

\section{Investigation of heterogeneity and bias}

As shown in Figs. 2-6, many of the meta-analyses showed significant heterogeneity $\left(I^{2}>50 \%\right.$ or chi square $\left.p<0.05\right)$. 


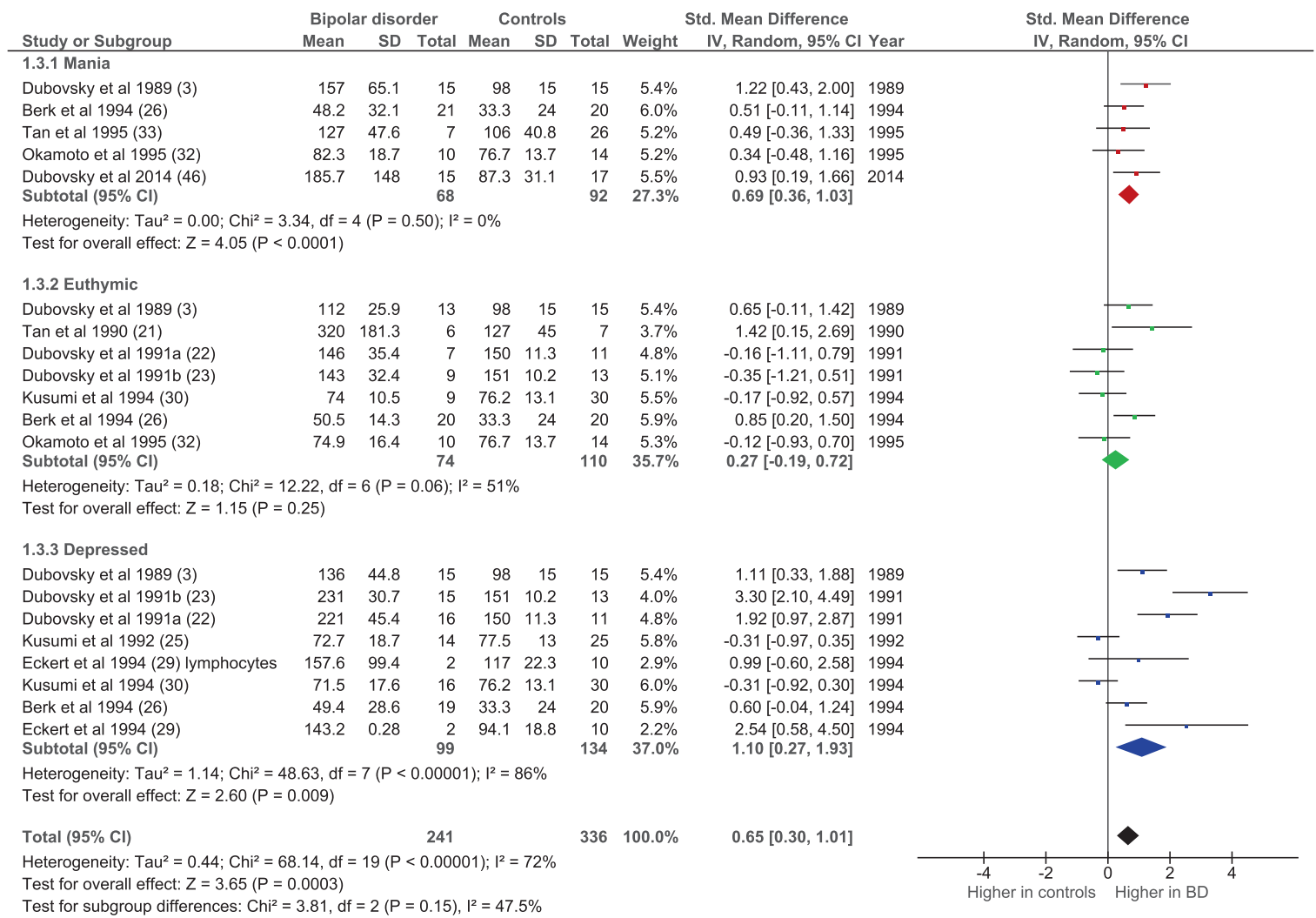

Fig. 3 Forest plot showing basal intracellular $\left[\mathrm{Ca}^{2+}\right]$ in mania (red), euthymia (green), and bipolar depression (blue) compared with controls. All studies are in platelets except where noted. IV inverse variance.

We could not find any overall explanations for this, although Hahn et al. [40] was an outlier in Figs. 2 and 6. Omission of this study reduced $I^{2}$ to below $50 \%$. It may be relevant that Hahn et al. [40] was the only meta-analysed study to use olfactory neurons. Inspection of funnel plots did not show any clear evidence of publication bias (for funnel plots and comments, see Supplementary Fig. 1).

The original study of $\left[\mathrm{Ca}^{2+}\right]_{\mathrm{b}}$ in bipolar disorder suggested greater inter-subject variability in cases than in controls [3]. To investigate this, we calculated variability (standard deviation divided by the mean) for each study included in Figs. 2 and 3. There was a trend towards greater variability in bipolar disorder $(0.31 \pm 0.18$ vs. $0.22 \pm 0.15$, $p=0.09, t$-test), which became nominally significant if one study with an outlying value in the control group [26] was excluded $(0.31 \pm 0.18$ vs. $0.20 \pm 0.11, p=0.02)$.

\section{Qualitative syntheses}

Not all data met our criteria for meta-analysis (usually because less than three studies had measured the same parameter). The main findings of these studies are summarised here.

We had intended to compare bipolar I with bipolar II disorder, but only two studies presented results in this way.
Hough et al. [36] found no differences in $\left[\mathrm{Ca}^{2+}\right]_{\mathrm{b}}$ or $\left[\mathrm{Ca}^{2+}\right]_{\mathrm{s}}$ between these subgroups in platelets or lymphocytes, whereas Uemura et al. [43] in a large sample of B-lymphoblasts, found $\left[\mathrm{Ca}^{2+}\right]_{\mathrm{b}}$ elevated in bipolar I but not bipolar II disorder.

Two studies measured parameters related to $\left[\mathrm{Ca}^{2+}\right]_{\mathrm{b}}$ but using different methods from the standard Fura2 technique. They did not find significant group differences [2, 38]. Berk et al. [34] measured ${ }^{45} \mathrm{Ca}^{2+}$ uptake into platelets, and found no differences between bipolar disorder subjects and controls.

In addition to the 5-HT and thrombin data summarised in Fig. 6, several other stimulants have been studied for their effect on $\left[\mathrm{Ca}^{2+}\right]_{\mathrm{s}}$. These include dopamine [26], platelet activating factor [27], phytohaemagglutinin [29], levetiracetam [47], odorants [40], and thapsigargin [41, 42]. Combinations of these and other stimulants have also been applied [3, 28, 36, 39, 46]. No consistent pattern of results has emerged, with many of the studies reporting no significant differences between bipolar disorder and control individuals.

Recent studies have begun to use iPSC-derived neuronal cells to examine $\mathrm{Ca}^{2+}$ functioning in bipolar disorder, usually as a small part of investigations focusing on other parameters and on lithium responsiveness of the cells [45, 48, 50]. Chen 


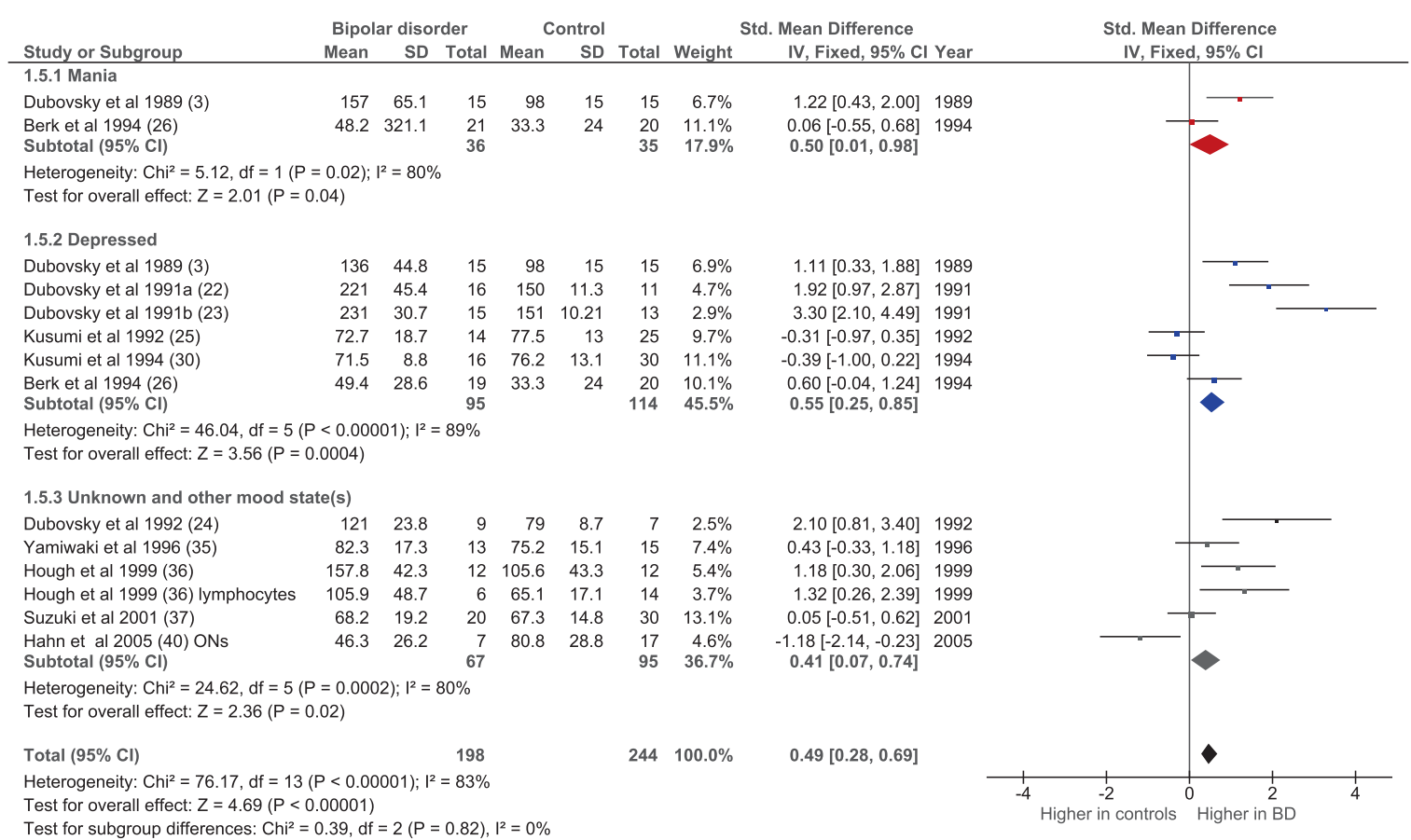

Fig. 4 Forest plot showing basal intracellular $\left[\mathrm{Ca}^{2+}\right]$ in unmedicated bipolar disorder, both overall and in mania (red), depressed (blue) and unknown or other mood state (grey) subgroups, compared with controls. All studies are in platelets except where noted. IV inverse variance, ONs olfactory neurons.

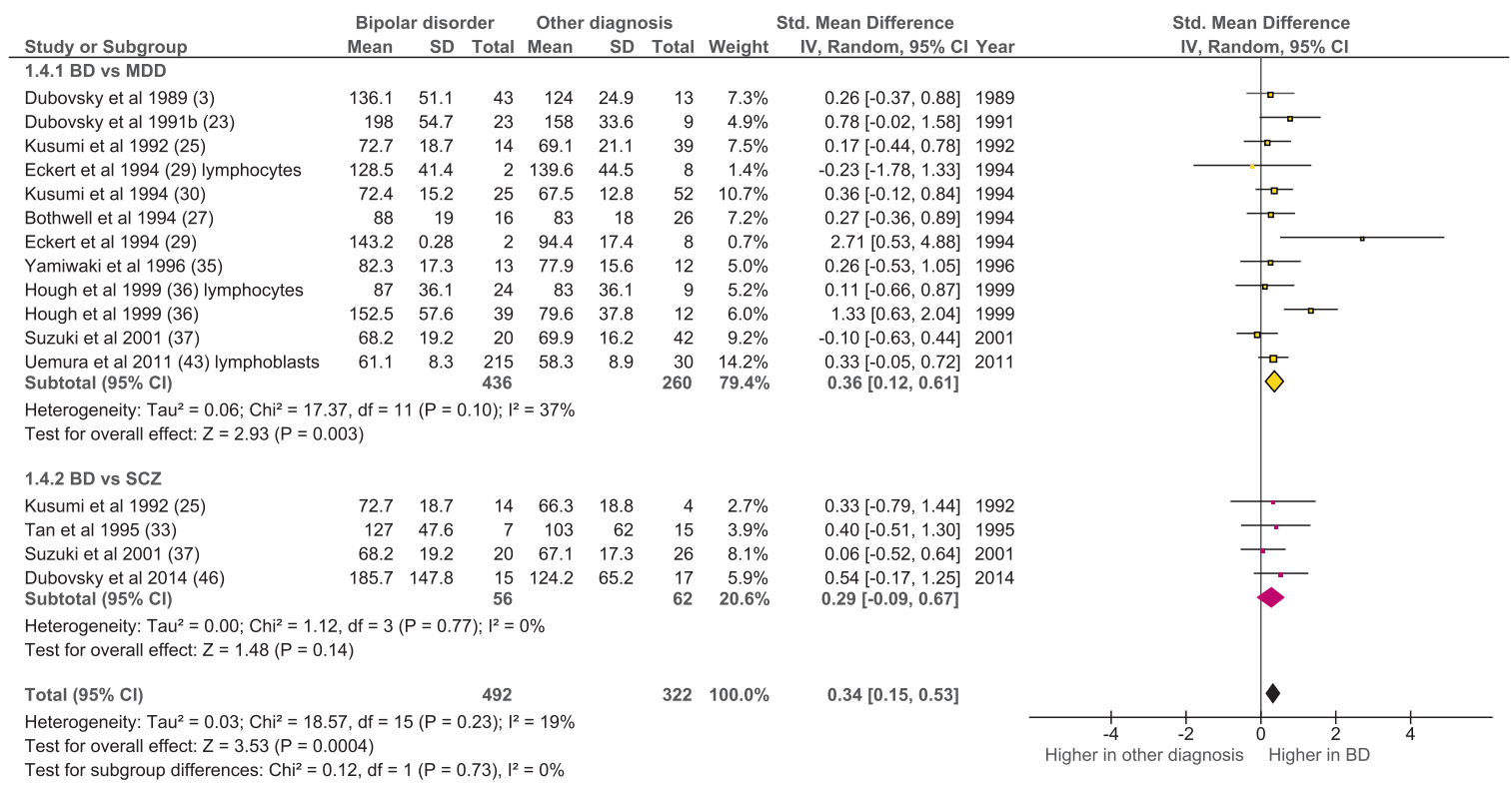

Fig. 5 Forest plot showing basal intracellular $\left[\mathrm{Ca}^{2+}\right]$ in bipolar disorder compared with unipolar depression (yellow) and schizophrenia (pink). All studies are in platelets except where noted. IV inverse variance.

et al. [45] pretreated induced neurons with lithium and showed a greater reduction in calcium transient and wave amplitude in neurons from individuals with bipolar disorder than from controls. Mertens et al. [48] reported a greater frequency of calcium events in iPSC-derived neurons from bipolar disorder individuals than from controls, and Tobe et al. [50] found altered kinetics of calcium transients in iPSC-derived neurons from bipolar subjects who had responded to lithium, but not in lithium non-responders, compared with healthy controls. Whilst all three studies contain some support for differential cellular $\mathrm{Ca}^{2+}$ signalling in bipolar disorder, all were based on very small samples, and 


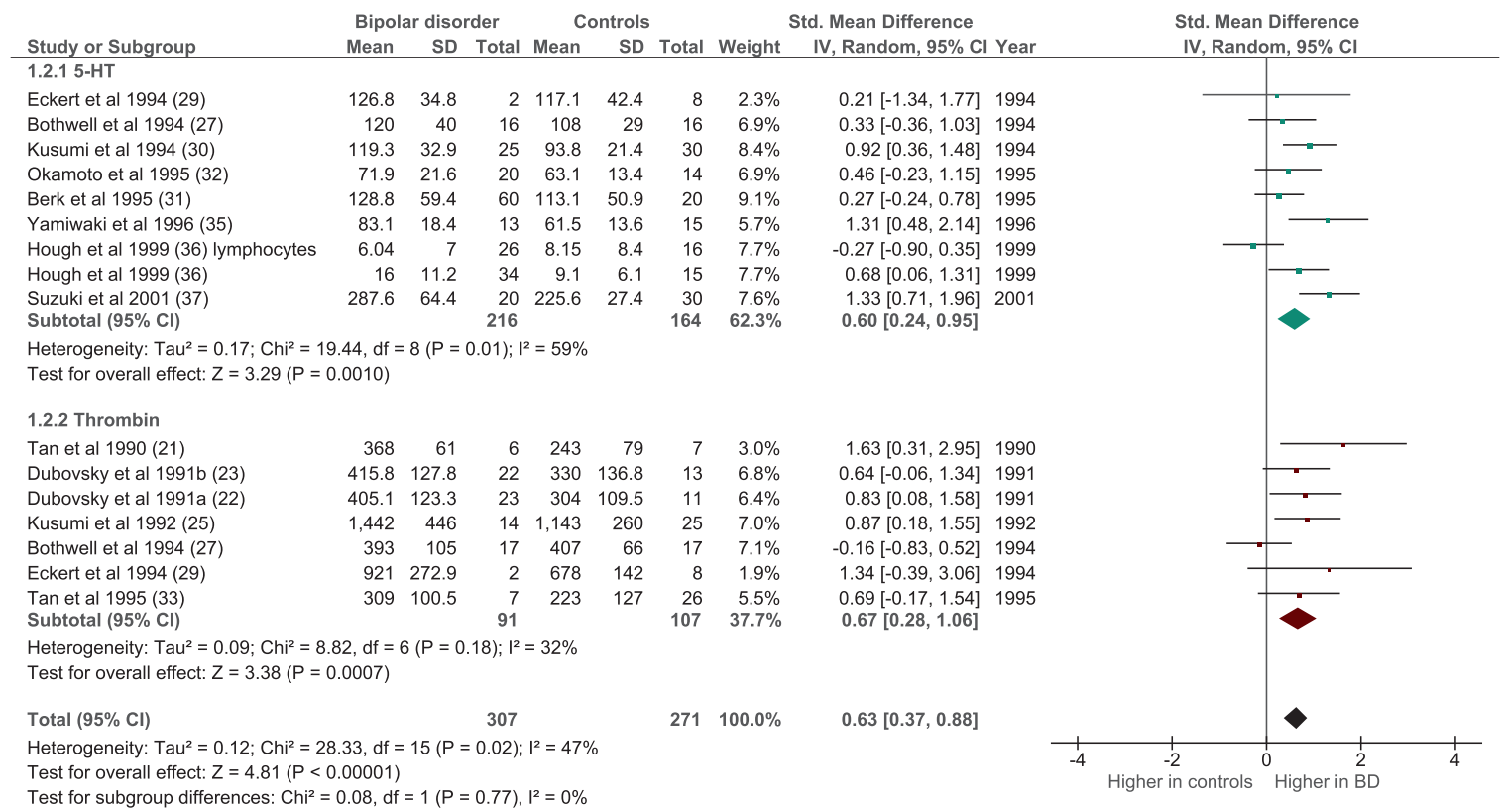

Fig. 6 Forest plot showing intracellular $\left[\mathrm{Ca}^{2+}\right]$ after stimulation with 5-HT (blue-green) or thrombin (dark red) in bipolar disorder compared with controls. All studies are in platelets except where noted. IV inverse variance.

no specific finding has yet been unequivocally replicated. Completing the results in neuronal-like cells, no differences have been observed in L-type calcium current properties in preliminary studies of olfactory neuronal cells from individuals with bipolar disorder compared with controls [44, 49].

\section{Discussion}

Calcium signalling has been the most studied in vitro parameter in bipolar disorder [51], resulting in 32 studies eligible for our systematic review and 21 available for metaanalysis. Our main finding is that there is robust evidence that intracellular $\left[\mathrm{Ca}^{2+}\right]$ is elevated in bipolar disorder (Figs. 2-6). This is seen in unmedicated patients, is present in platelets and lymphocytes, occurs in mania and depression, and under basal conditions and in response to stimuli. The findings thus provide strong support for altered calcium functioning in bipolar disorder.

Before proceeding, several potential confounders should be considered. Intracellular $\left[\mathrm{Ca}^{2+}\right]$ can be modestly affected by a range of demographic factors including age, gender, ethnicity, genetic factors, and possibly by blood pressure [52-55]. Whilst most studies have matched case and control groups by age and gender, the other factors have rarely if ever been mentioned or controlled for. The most relevant of these potential confounders is blood pressure, since there is a higher rate of cardiovascular disease and hypertension in patients with bipolar disorder [56, 57]. However, it seems unlikely that this could explain more than a small fraction of the diagnostic differences, especially since a relationship between blood pressure and intracellular $\left[\mathrm{Ca}^{2+}\right]$ has not been consistently observed [52, 54, 55]. Nevertheless, future studies will benefit from a more careful assessment of, and control for, blood pressure and other cardiovascular and metabolic indices.

The fact that the differences were seen in unmedicated patients, and in lymphoblasts, in which any residual drug effects would likely be removed, argues against the elevated $\left[\mathrm{Ca}^{2+}\right]$ in bipolar disorder being attributable to lithium or other psychotropic drugs. A full discussion of whether bipolar disorder medications normalise cellular $\left[\mathrm{Ca}^{2+}\right]$ is beyond the scope of this systematic review. However, there is considerable evidence that this may be the case for lithium [3, 18, 20, 58], with weaker evidence for other mood stabilisers [59]. The question of how medication impacts on $\left[\mathrm{Ca}^{2+}\right]$ is relevant to the finding that $\left[\mathrm{Ca}^{2+}\right]_{b}$ was not significantly altered in bipolar disorder patients in remission (Fig. 4). It is possible that altered $\left[\mathrm{Ca}^{2+}\right]_{b}$ is only seen during a mood episode; alternatively, it may be a trait which is present throughout the illness but which is normalised by medication (since all euthymic patients were on medication). It will be valuable in future studies to include euthymic patients who are medication free to address this issue. It will be of even more interest to study $\left[\mathrm{Ca}^{2+}\right]_{\mathrm{b}}$ (and $\left[\mathrm{Ca}^{2+}\right]_{\mathrm{s}}$ ) longitudinally, including in high-risk subjects, to determine the temporal trajectory of elevated $\left[\mathrm{Ca}^{2+}\right]$ across the course of bipolar disorder.

Cellular $\left[\mathrm{Ca}^{2+}\right]$ has been measured in other disorders, notably unipolar (major) depression and in schizophrenia. Studies which also included a bipolar disorder group were included in a meta-analysis (Fig. 5), revealing that $\left[\mathrm{Ca}^{2+}\right]_{b}$ 
is lower (or increased less) in unipolar depression than in bipolar disorder. Bipolar disorder did not differ significantly from schizophrenia, albeit based on a much smaller dataset and with a consequent lack of power for this comparison. Regarding the overlap with schizophrenia, it is notable that there is some evidence that the elevation of $\left[\mathrm{Ca}^{2+}\right]_{b}$ is seen in bipolar I rather than bipolar II, at least in lymphoblasts [43]. There were insufficient data to review systematically the diagnostic specificity of $\left[\mathrm{Ca}^{2+}\right]_{\mathrm{s}}$, but one study suggested a greater response in bipolar disorder than in major depression [60]. Overall, the data overall suggest that raised intracellular $\left[\mathrm{Ca}^{2+}\right]$ is prominent in, but probably not restricted to, bipolar disorder.

Intracellular $\left[\mathrm{Ca}^{2+}\right]$ is subject to intricate and complex regulation [61-63], and various explanations have been proffered for the increased $\left[\mathrm{Ca}^{2+}\right]$ seen in bipolar disorder [18-20], including whether the primary cause is excess influx, decreased efflux, or altered compartmentalisation of $\left[\mathrm{Ca}^{2+}\right]$ within the cell. The latter view links $\left[\mathrm{Ca}^{2+}\right]$ to mitochondrial and endoplasmic reticulum theories of the disorder, since these organelles are critical to regulation of intracellular $\left[\mathrm{Ca}^{2+}\right][19,64]$. Altered expression or function of molecules involved in $\mathrm{Ca}^{2+}$ fluxes and $\mathrm{Ca}^{2+}$ buffering in bipolar disorder has also been reported (e.g. refs. [65-67] and see Supplementary Table 1). The results of this systematic review do not bear directly upon these issues, but do provide a strong rationale to investigate further the explanation for the abnormality. One point to emphasise that the meta-analysed studies only measure free intracellular $\mathrm{Ca}^{2+}$ [68]. This is a tiny fraction $(<1 \%)$ of total cellular $\left[\mathrm{Ca}^{2+}\right]$, with the vast majority being sequestered in the organelles mentioned and in membrane-associated microdomains. As such, the measured parameter is the tip of the cellular $\left[\mathrm{Ca}^{2+}\right]$ iceberg, and hence the $25-30 \%$ elevations seen in bipolar disorder could result from a small difference in one or more of the intracellular calcium stores and the molecules which regulate them. That is, the core cellular 'calcium abnormality' of bipolar disorder could be extremely subtle. It remains to be determined whether the elevation in free intracellular $\left[\mathrm{Ca}^{2+}\right]$ in bipolar disorder is itself deleterious, or simply a marker of the underlying disturbance.

The recent resurgence of interest in calcium in bipolar disorder has been fostered by the genomic data showing that VGCCs are part of the genetic risk architecture, implicating a role for $\mathrm{Ca}^{2+}$ signalling in the disorder [12, $16,17]$. The question arises as to whether the genetic findings are directly related to the elevated intracellular $\left[\mathrm{Ca}^{2+}\right]$ observed in platelets and lymphocytes. At first sight this seems unlikely since VGCCs have been considered to be signature channels of cellular excitability [69] (i.e. limited to neurons and myocytes), with $\left[\mathrm{Ca}^{2+}\right]$ in nonexcitable cells being controlled by other mechanisms such as store-operated $\mathrm{Ca}^{2+}$-entry. However, there is increasing evidence that VGCCs are in fact expressed and functional in many non-excitable cells [69], including in some lymphocytes [70, 71] and in glia [72-74]. It therefore cannot be excluded that VGCCs have a role in $\left[\mathrm{Ca}^{2+}\right]$ regulation in many cell types, although this would seem likely to be at most a minor contribution to the results reported here, especially since VGCCs are not expressed in platelets or their megakaryocyte precursors [75]. Finally, it would be of interest to study intracellular $\left[\mathrm{Ca}^{2+}\right]$ in glia in bipolar disorder, since these cells are implicated in its pathophysiology [76, 77], and $\mathrm{Ca}^{2+}$ dysregulation in the disorder may involve these cells as well as the presumed primary neuronal locus of dysfunction. Despite the uncertainties as to its cause and molecular basis, the increase in intracellular $\left[\mathrm{Ca}^{2+}\right]$ found in bipolar disorder is broadly supportive of the possibility that novel calcium channel antagonists, or related drugs acting upon calcium signalling, could be of potential therapeutic value, especially if designed to be brain selective [78-80].

Acknowledgements We thank Andrea Cipriani and Antony Galione for expert advice, and the authors who kindly provided data clarifications on request. Work supported by the National Institute for Health Research (NIHR) Oxford Health Biomedical Research Centre. The views expressed are those of the authors and not necessarily those of the National Health Service, NIHR, or the Department of Health and Social Care.

Author contributions PJH and EMT designed the study. PJH, NA-J and AM performed literature searches. PJH, NH and EMT extracted data. PJH and EMT conducted the meta-analyses. PJH wrote the paper with input from EMT. All authors revised and approved the paper.

\section{Compliance with ethical standards}

Conflict of interest The authors declare that they have no conflict of interest.

Publisher's note Springer Nature remains neutral with regard to jurisdictional claims in published maps and institutional affiliations.

Open Access This article is licensed under a Creative Commons Attribution 4.0 International License, which permits use, sharing, adaptation, distribution and reproduction in any medium or format, as long as you give appropriate credit to the original author(s) and the source, provide a link to the Creative Commons license, and indicate if changes were made. The images or other third party material in this article are included in the article's Creative Commons license, unless indicated otherwise in a credit line to the material. If material is not included in the article's Creative Commons license and your intended use is not permitted by statutory regulation or exceeds the permitted use, you will need to obtain permission directly from the copyright holder. To view a copy of this license, visit http://creativecommons. org/licenses/by/4.0/.

\section{References}

1. Weston PG, Howard MQ. The determination of sodium, potassium, calcium and magnesium in the blood and spinal fluid of 
patients suffering from manic depressive insanity. Arch Neurol Psychiatry. 1922;8:179-83.

2. Bowden CL, Huang LG, Javors MA, Johnson JM, Seleshi E, McIntyre $\mathrm{K}$, et al. Calcium function in affective disorders and healthy controls. Biol Psychiatry. 1988;23:367-76.

3. Dubovsky SL, Christiano J, Daniell L, Franks RD, Murphy J, Adler L, et al. Increased platelet intracellular calcium concentration in patients with bipolar affective disorders. Arch Gen Psychiatry. 1989;46:632-8.

4. Greer PL, Greenberg ME. From synapse to nucleus: calciumdependent gene transcription in the control of synapse development and function. Neuron. 2008;59:846-60.

5. Bading $\mathrm{H}$. Nuclear calcium signalling in the regulation of brain function. Nat Rev Neurosci. 2013;14:593-608.

6. Baker KD, Edwards TM, Rickard NS. The role of intracellular calcium stores in synaptic plasticity and memory consolidation. Neurosci Biobehav Rev. 2013;37:1211-39.

7. Nanou E, Catterall WA. Calcium channels, synaptic plasticity, and neuropsychiatric disease. Neuron. 2018;98:466-81.

8. Dittman JS, Ryan TA. The control of release probability at nerve terminals. Nat Rev Neurosci. 2019;20:177-86.

9. Dubovsky SL, Franks RD. Intracellular calcium ions in affective disorders: a review and an hypothesis. Biol Psychiatry. 1983;18:781-97.

10. Glen AI. Lithium prophylaxis of recurrent affective disorders. J Affect Disord. 1985;8:259-65.

11. Helmeste DM, Tang SW. The role of calcium in the etiology of the affective disorders. Jpn J Pharmacol. 1998;77:107-16.

12. Heyes S, Pratt WS, Rees E, Dahimene S, Ferron L, Owen MJ, et al. Genetic disruption of voltage-gated calcium channels in psychiatric and neurological disorders. Prog Neurobiol. 2015;134:36-54.

13. Harrison PJ. Molecular neurobiological clues to the pathogenesis of bipolar disorder. Curr Opin Neurobiol. 2016;36:1-6.

14. Cipriani A, Saunders K, Attenburrow MJ, Stefaniak J, Panchal $\mathrm{P}$, Stockton $\mathrm{S}$, et al. A systematic review of calcium channel antagonists in bipolar disorder and some considerations for their future development. Mol Psychiatry. 2016;21: 1324-32.

15. Houghton KT, Forrest A, Awad A, Atkinson LZ, Stockton S, Harrison PJ, et al. Biological rationale and potential clinical use of gabapentin and pregabalin in bipolar disorder, insomnia and anxiety: protocol for a systematic review and meta-analysis. BMJ Open. 2017;7:e013433.

16. Harrison PJ, Geddes JR, Tunbridge EM. The emerging neurobiology of bipolar disorder. Trends Neurosci. 2018;41:18-30.

17. Harrison PJ, Tunbridge EM, Dolphin AC, Hall J. Voltage-gated calcium channel blockers for psychiatric disorders: genomic reappraisal. Br J Psychiatry. 2019. https://doi.org/10.1192/bjp. 2019.157.

18. Warsh JJ, Andreopoulos S, Li PP. Role of intracellular calcium signaling in the pathophysiology and pharmacotherapy of bipolar disorder: current status. Clin Neurosci Res. 2004;4: 201-13.

19. Quiroz JA, Gray NA, Kato T, Manji HK. Mitochondrially mediated plasticity in the pathophysiology and treatment of bipolar disorder. Neuropsychopharmacology. 2008;33:2551-65.

20. Berridge MJ. Calcium signalling and psychiatric disease: bipolar disorder and schizophrenia. Cell Tissue Res. 2014;357: 477-92.

21. Tan CH, Javors MA, Seleshi E, Lowrimore PA, Bowden CL. Effects of lithium on platelet ionic intracellular calcium concentration in patients with bipolar (manic-depressive) disorder and healthy controls. Life Sci. 1990;46:1175-80.

22. Dubovsky SL, Lee C, Christiano J, Murphy J. Lithium lowers platelet intracellular ion concentration in bipolar patients. Lithium. 1991a;2:167-74.
23. Dubovsky SL, Lee C, Christiano J, Murphy J. Elevated platelet intracellular calcium concentration in bipolar depression. Biol Psychiatry. 1991b;29:441-50.

24. Dubovsky SL, Murphy J, Thomas M, Rademacher J. Abnormal intracellular calcium ion concentration in platelets and lymphocytes of bipolar patients. Am J Psychiatry. 1992;149:118-20.

25. Kusumi I, Koyama T, Yamashita I. Thrombin-induced platelet calcium mobilization is enhanced in bipolar disorders. Biol Psychiatry. 1992;32:731-4.

26. Berk M, Bodemer W, van Oudenhove T, Butkow N. Dopamine increases platelet intracellular calcium in bipolar affective disorder and controls. Int Clin Psychopharmacol. 1994;9:291-3.

27. Bothwell RA, Eccleston D, Marshall E. Platelet intracellular calcium in patients with recurrent affective disorders. Psychopharmacology. 1994;114:375-81.

28. Dubovsky SL, Thomas M, Hijazi A, Murphy J. Intracellular calcium signalling in peripheral cells of patients with bipolar affective disorder. Eur Arch Psychiatry Clin Neurosci. 1994;243: 229-34.

29. Eckert A, Gann H, Riemann D, Aldenhoff J, Muller WE. Platelet and lymphocyte free intracellular calcium in affective disorders. Eur Arch Psychiatry Clin Neurosci. 1994;243:235-9.

30. Kusumi I, Koyama T, Yamashita I. Serotonin-induced platelet intracellular calcium mobilization in depressed patients. Psychopharmacology. 1994;113:322-7.

31. Berk M, Bodemer W, Van Oudenhove T, Butkow N. The platelet intracellular calcium response to serotonin is augmented in bipolar manic and depressed patients. Hum Psychopharmacol. 1995; 10:189-93.

32. Okamoto Y, Kagaya A, Shinno H, Motohashi N, Yamawaki S. Serotonin-induced platelet calcium mobilization is enhanced in mania. Life Sci. 1995;56:327-32.

33. Tan $\mathrm{CH}$, Lee HS, Kua EH, Peh LH. Resting and thrombinstimulated cytosolic calcium in platelets of patients with alcoholic withdrawal, bipolar manic disorder and chronic schizophrenia. Life Sci. 1995;56:1817-23.

34. Berk M, Kirchmann NH, Butkow N. Lithium blocks $45 \mathrm{Ca} 2$ +uptake into platelets in bipolar affective disorder and controls. Clin Neuropharmacol. 1996;19:48-51.

35. Yamawaki S, Kagaya A, Okamoto Y, Shimizu M, Nishida A, Uchitomi Y. Enhanced calcium response to serotonin in platelets from patients with affective disorders. J Psychiatry Neurosci. 1996;21:321-4.

36. Hough C, Lu SJ, Davis CL, Chuang DM, Post RM. Elevated basal and thapsigargin-stimulated intracellular calcium of platelets and lymphocytes from bipolar affective disorder patients measured by a fluorometric microassay. Biol Psychiatry. 1999;46:247-55.

37. Suzuki K, Kusumi I, Sasaki Y, Koyama T. Serotonin-induced platelet intracellular calcium mobilization in various psychiatric disorders: is it specific to bipolar disorder? J Affect Disord. 2001;64:291-6.

38. El Khoury A, Petterson U, Kallner G, Aberg-Wistedt A, StainMalmgren R. Calcium homeostasis in long-term lithium-treated women with bipolar affective disorder. Prog Neuropsychopharmacol Biol Psychiatry. 2002;26:1063-9.

39. Kato T, Ishiwata M, Mori K, Washizuka S, Tajima O, Akiyama T, et al. Mechanisms of altered $\mathrm{Ca}^{2+}$ signalling in transformed lymphoblastoid cells from patients with bipolar disorder. Int $\mathbf{J}$ Neuropsychopharmacol. 2003;6:379-89.

40. Hahn CG, Gomez G, Restrepo D, Friedman E, Josiassen R, Pribitkin EA, et al. Aberrant intracellular calcium signaling in olfactory neurons from patients with bipolar disorder. Am J Psychiatry. 2005;162:616-8.

41. Akimoto T, Kusumi I, Suzuki K, Koyama T. Effects of calmodulin and protein kinase $\mathrm{C}$ modulators on transient $\mathrm{Ca} 2+$ increase and capacitative $\mathrm{Ca} 2+$ entry in human platelets: relevant to 
pathophysiology of bipolar disorder. Prog Neuropsychopharmacol Biol Psychiatry. 2007;31:136-41.

42. Perova T, Wasserman MJ, Li PP, Warsh JJ. Hyperactive intracellular calcium dynamics in B lymphoblasts from patients with bipolar I disorder. Int J Neuropsychopharmacol. 2008;11:185-96.

43. Uemura T, Green M, Corson TW, Perova T, Li PP, Warsh JJ. Bcl2 SNP rs956572 associates with disrupted intracellular calcium homeostasis in bipolar I disorder. Bipolar Disord. 2011;13:41-51.

44. Solis-Chagoyan H, Calixto E, Figueroa A, Montano LM, Berlanga C, Rodriguez-Verdugo MS, et al. Microtubule organization and Ltype voltage-activated calcium current in olfactory neuronal cells obtained from patients with schizophrenia and bipolar disorder. Schizophr Res. 2013;143:384-9.

45. Chen HM, DeLong CJ, Bame M, Rajapakse I, Herron TJ, McInnis MG, et al. Transcripts involved in calcium signaling and telencephalic neuronal fate are altered in induced pluripotent stem cells from bipolar disorder patients. Transl Psychiatry. 2014;4: e375.

46. Dubovsky SL, Daurignac E, Leonard KE. Increased platelet intracellular calcium ion concentration is specific to bipolar disorder. J Affect Disord. 2014;164:38-42.

47. Dubovsky SL, Daurignac E, Leonard KE, Serotte JC. Levetiracetam, calcium antagonism, and bipolar disorder. J Clin Psychopharmacol. 2015;35:422-7.

48. Mertens J, Wang QW, Kim Y, Yu DX, Pham S, Yang B, et al. Differential responses to lithium in hyperexcitable neurons from patients with bipolar disorder. Nature. 2015;527:95-9.

49. Benitez-King G, Valdes-Tovar M, Trueta C, Galvan-Arrieta T, Argueta J, Alarcon S, et al. The microtubular cytoskeleton of olfactory neurons derived from patients with schizophrenia or with bipolar disorder: implications for biomarker characterization, neuronal physiology and pharmacological screening. Mol Cell Neurosci. 2016;73:84-95.

50. Tobe BTD, Crain AM, Winquist AM, Calabrese B, Makihara H, Zhao WN, et al. Probing the lithium-response pathway in hiPSCs implicates the phosphoregulatory set-point for a cytoskeletal modulator in bipolar pathogenesis. Proc Natl Acad Sci USA. 2017;114:E4462-71

51. Viswanath B, Jose SP, Squassina A, Thirthalli J, Purushottam M, Mukherjee O, et al. Cellular models to study bipolar disorder: a systematic review. J Affect Disord. 2015;184:36-50.

52. Bruschi G, Bruschi ME, Caroppo M, Orlandini G, Spaggiari M, Cavatorta A. Cytoplasmic free $[\mathrm{Ca} 2+]$ is increased in the platelets of spontaneously hypertensive rats and essential hypertensive patients. Clin Sci. 1985;68:179-84.

53. Duggan J, Kilfeather S, Sheridan J, O'Brien E, O'Malley K. The effects of age on platelet intracellular free calcium concentration in normotensives and hypertensives. J Hypertension. 1991;9:845-50.

54. Williams PD, Puddey IB, Martin NG, Beilin LJ. Platelet cytosolic free calcium-concentration, total plasma-concentration and bloodpressure in normal twins. A genetic analysis. Clin Sci. 1992;82: 493-504.

55. Gardner JP, Cho JH, Skurnick JH, Awad G, Gutkin M, Byrd LH, et al. Blood pressure inversely correlates with thrombin-evoked calcium rise in platelets. Hypertension. 1994;23:703-9.

56. Correll CU, Solmi M, Veronese N, Bortolato B, Rosson S, Santonasto $\mathrm{P}$, et al. Prevalence, incidence and mortality from cardiovascular disease in patients with pooled and specific severe mental illness: a large-scale meta-analysis of 3,211,768 patients and 113,383,368 controls. World Psychiatry. 2017;16:163-80.

57. Goldstein BI. Bipolar disorder and the vascular system: mechanisms and new prevention opportunities. Can J Cardiol. 2017; 33:1565-76.

58. Wasserman MJ, Corson TW, Sibony D, Cooke RG, Parikh SV, Pennefather PS, et al. Chronic lithium treatment attenuates intracellular calcium mobilization. Neuropsychopharmacology. 2004;29:759-69.

59. Perova T, Kwan M, Li PP, Warsh JJ. Differential modulation of intracellular $\mathrm{Ca} 2+$ responses in B lymphoblasts by mood stabilizers. Int J Neuropsychopharmacol. 2010;13:693-702.

60. Kusumi I, Suzuki K, Sasaki Y, Kameda K, Koyama T. Treatment response in depressed patients with enhanced $\mathrm{Ca}$ mobilization stimulated by serotonin. Neuropsychopharmacology. 2000;23: 690-6.

61. Missaien L, Robberecht W, Van Den Bosch L, Callewaert G, Parys JB, Wuytack F, et al. Abnormal intracellular $\mathrm{Ca}^{2+}$ homeostasis and disease. Cell Calcium. 2000;28:1-21.

62. Brini M, Carafoli E. Calcium pumps in health and disease. Physiol Rev. 2008;89:1341-78.

63. Santulli G, Nakashima R, Yuan Q, Marks AR. Intracellular calcium release channels: an update. J Physiol. 2017;595:3041-51.

64. Mekahli D, Bulltynck G, Parys JB, De Smedt H, Missiaen L. Endoplasmic-reticulum calcium depletion and disease. Cold Spring Harb Perspect Biol. 2011;3:a004317.

65. Emamghoreishi M, Li PP, Schlichter L, Parikh SV, Cooke R, Warsh JJ. Associated disturbances in calcium homeostasis and G protein-mediated cAMP signaling in bipolar I disorder. Biol Psychiatry. 2000;48:665-73.

66. Roedding AS, Gao AF, Au-Yeung W, Scarcelli T, Li PP, Warsh JJ. Effect of oxidative stress on TRPM2 and TRPC 3 channels in B lymphoblast cells in bipolar disorder. Bipolar Disord. 2012; 14:151-61

67. Hayashi A, Le Gal K, Sodersten K, Vizlin-Hodzic D, Agren H, Funa K. Calcium-dependent intracellular signal pathways in primary cultured adipocytes and ANK3 gene variation in patients with bipolar disorder and healthy controls. Mol Psychiatry. 2015;20:931-40.

68. Paredes RM, Etzler J, Watts LT, Zheng W, Lechleiter JD. Chemical calcium indicators. Methods. 2008;46:143-51.

69. Davenport B, Li Y, Heizer JW, Schmitz C, Perraud A-L. Signature channels of excitability no more: L-type channels in immune cells. Front Immunol. 2015;6:375.

70. Kotturi MF, Jefferies WA. Molecular characterization of L-type calcium channel splice variants expressed in human $\mathrm{T}$ lymphocytes. Mol Immunol. 2005;42:1461-74.

71. Badou A, Jha MK, Matza D, Flavell RA. Emerging roles of Ltype voltage-gated and other calcium channels in T lymphocytes. Front Immunol. 2013;4:243.

72. Sharma P, Ping L. Calcium ion influx in microglial cells: physiological and therapeutic significance. J Neurosci Res. 2014;92: 409-23.

73. Wang F, Du T, Liang C, Verkhratsky A, Peng L. Ammonium increases $\mathrm{Ca}^{2+}$ signalling and upregulates expression of $\mathrm{Ca}_{\mathrm{V}} 1.2$ gene in astrocytes in primary culture and in the in vivo brain. Acta Physiol. 2015;214:261-74.

74. Cheli VT, Gonzalez DAS, Lama TN, Spreuer V, Handley V, Murphy GG, et al. Conditional deletion of the L-type calcium channel $\mathrm{Ca}_{\mathrm{V}} 1.2$ in oligodendrocyte precursor cells affects postnatal myelination in mice. J Neurosci. 2016;36:10853-69.

75. Wright JR, Amisten S, Goodall AH, Mahaut-Smith MP. Transcriptomic analysis of the ion channelome of human platelets and megakaryocytic cell lines. Thromb Haemost. 2016;116: 272-84.

76. Cotter DR, Pariante CM, Everall IP. Glial cell abnormalities in major psychiatric disorders: the evidence and implications. Brain Res Bull. 2001;55:585-95.

77. Harrison PJ, Colbourne L, Harrison $\mathrm{CH}$. The neuropathology of bipolar disorder: systematic review and meta-analysis. Mol Psychiatry. 2018. https://doi.org/10.1038/s41380-018-0213-3.

78. Atkinson LZ, Colbourne L, Smith A, Harmer CH, Nobre AC, Rendell J, et al. The Oxford study of calcium channel antagonism, 
cognition, mood instability and sleep (OxCaMS): study protocol for a randomised controlled, experimental medicine study. Trials. 2019;20:120.

79. Clark M, Wrzesinski T, Garcia-Bea A, Kleinman J, Hyde T, Weinberger DR, et al. Long-read sequencing reveals the splicing profile of the calcium channel gene CACNA1C in human brain.
Mol Psychiatry. 2019. https://doi.org/10.1038/s41380-019-0583-1. [Epub ahead of print].

80. Dubovsky SL. Applications of calcium channel blockers in psychiatry: pharmacokinetic and pharmacodynamic aspects of treatment of bipolar disorder. Expert Opin Drug Metab Toxicol. 2019;15:35-47. 